\title{
TEORIA DOS SISTEMAS AUTOPOIÉTICOS E CONSTITUIÇÃO: LUHMANN E O SUPREMO TRIBUNAL FEDERAL ${ }^{1}$
}

\section{THEORY OF AUTOPOIETIC SYSTEMS AND CONSTITUTION: LUHMANN AND THE FEDERAL SUPREME COURT}

\author{
Germano Schwartz \\ Douglas Ribeiro**
}

\begin{abstract}
Resumo: No Direito brasileiro, o Supremo Tribunal Federal é o guardião da Constituição. Ao verificar citações à teoria de Luhmann em suas decisões, viabiliza-se uma observação sobre a observação do Supremo Tribunal Federal sobre a observação de Luhmann, principalmente sobre aspectos constitucionais. Nesse contexto, o presente artigo pretende analisar como a teoria de Niklas Luhmann foi mencionada em decisões do Supremo Tribunal Federal, demonstrando os erros, insuficiências ou mesmo falta de clareza na interpretação, com vistas a aclarar certas tendências equivocadas e, igualmente, explicitar pontos importantes da teoria dos sistemas sociais autopoiéticos.
\end{abstract}

Palavras-chave: Luhmann, Teoria dos Sistemas, Supremo Tribunal Federal, Constituição.

Abstract: In the brazilian law, the Supreme Federal Court is the guardian of Brazil's Constitution. By verifying Luhmann's theory quotes in their decisions it allows an observation on Supreme Federal Court's observation on Luhmann's observation, mainly on constitutional issues. In this context, the present article intends to analyze how Niklas Luhmann's theory was mentioned in decisions of the Supreme Federal Court, showing the errors, incompleteness or even lack of clarity on the interpretation in order to clarify important points of the theory of autopoietic social systems.

Keywords: Luhmann, System Theory, Supreme Federal Court, Constitution.

\section{INTRODUÇÃO}

As teorias são relevantes cientificamente quando correm o risco de serem consideradas não verdadeiras. Assim, a Ciência obriga-se a proceder de maneira

\footnotetext{
* Bolsista em Produtividade e Pesquisa do CNPq (Nível 2). Coordenador do Mestrado em Direito e Sociedade do Unilasalle/Canoas. Diretor Executivo Acadêmico da Escola de Direito das FMU. Pós-Doutor em Direito (University of Reading). Doutor em Direito (Unisinos) com estágio doutoral em Paris X Nanterre. Professor do Mestrado em Saúde e Desenvolvimento do Unilasalle. Secretário do Research Committee on Sociology of Law da International Sociological Association. Membro do Comitê Executivo do World Consortium on Sociology of Law. E-mail: germano.schwartz@globo.com.

** Mestre em Direito e Sociedade (Unilasalle-Canoas). Especialista em Direito Tributário (UFRGS). Email: dougcrib@gmail.com.
} 
Teoria dos sistemas autopoiéticos e constituição:

Luhmann e o Supremo Tribunal Federal

arriscada, conforme já disse Niklas Luhmann, citando o postulado da falseabilidade de Karl Popper ${ }^{2}$.

Ademais, a escrita possibilitou alcançar os ausentes no espaço e no tempo, de tal modo que é motivo de contínua reobservação mediante novas distinções. Com isso, permite-se a formação de opiniões/interpretações diferentes sobre textos idênticos. E, por sua vez, a interpretação pode produzir novos textos/escritos que poderão gerar novas distinções (LUHMANN, 2007).

Em vista disso, os diversos artigos e livros que Niklas Luhmann escreveu estão sujeitos à crítica, e, ainda, as variadas interpretações sobre seus artigos e livros são novas observações. Não se pode, por um lado, isentá-lo de opiniões divergentes e tampouco, por outro, rejeitá-lo prematuramente: "Lendo algumas críticas mais severas à teoria autopoiética, tem-se a distinta impressão de que esses críticos vêem a teoria quase como uma fé religiosa (ou diabólica), e seus partidários, como seguidores fanáticos de líderes carismáticos, mas desorientados" (KING, 2009, p. 44).

Ocorre que se percebe haver, demasiadamente, uma rejeição sumária sobre a teoria de Luhmann (KING, 2009). Embora muito debatida e criticada, a teoria dos sistemas sociais autopoiético é, porém, pouco compreendida. Dessa maneira, as críticas são, geralmente, oriundas de uma leitura superficial como claramente demonstra Michael King em texto escrito justamente com o propósito de rebater essas espécies críticas (KING, 2009).

Assim, o presente artigo busca analisar como a teoria de Niklas Luhmann foi mencionada em decisões do Supremo Tribunal Federal (STF), demonstrando erros, insuficiências ou mesmo falta de clareza na interpretação, com vistas a aclarar certas tendências equivocadas e, igualmente, explicitar pontos importantes da teoria. Apesar de não ter sido objeto do presente artigo, não se pode olvidar de que Luhmann foi, indiretamente, alvo de debate em julgamento histórico do STF no caso conhecido como mensalão, objeto da Ação Penal 470, ao ser citado Gunther Jakobs.

Nesse contexto de Tribunal Constitucional ${ }^{3}$, a abordagem deste estudo se vincula a um dos temas do momento na Sociologia do Direito e de que Luhmann é precursor, qual seja, a Sociologia das Constituições.

Atualmente, com base em Luhmann, exsurgem muitos debates sobre a Constituição sob uma perspectiva sociológica. A partir deles é mais fácil dizer o que a Constituição era, do que dizer o que a Constituição é, consoante explanam Alberto Febbrajo e Giancarlo Corsi ${ }^{4}$. A seu turno, a noção moderna de soberania constitucional 
deve ser reconsiderada em virtude da constitucionalização de diferentes setores da sociedade global, assim conclui Jirí Pribán (PRIBAN, 2015).

O Judiciário, por sua vez, ocupa a posição central no sistema do Direito, cujas operações só reproduzem operações filtradas - e não filtrantes -, colocando em prática o código (lícito/ilícito) e os programas jurídicos, fazendo uso reservado do símbolo circundante da validade jurídica (CLAM; LUHMANN, 1990). No caso do STF, a sua relação com a Constituição é mais forte, destacando-se que a "atuação intensa do Poder Judiciário na efetivação dos direitos fundamentais deve ser entendida como critério decisório a embasar a dinâmica autopoiética e organizacional do sistema jurídico" (SCHWARTS, 2007a, p. 11).

No Direito brasileiro, o STF é órgão do Judiciário, guardião da Constituição Federal: o último intérprete das normas constitucionais ${ }^{5}$. As citações à teoria de Luhmann em determinadas decisões do STF viabilizam uma observação sobre a observação do STF sobre a observação de Luhmann. Tratando-se de decisões sobre a constitucionalidade/inconstitucionalidade, torna-se importante esclarecer principalmente aspectos sobre a Constituição com base na teoria luhmanniana.

Ora, a incompreensão sobre a teoria de Niklas Luhmann implica uma conexão de interpretações insuficientes ou errôneas que, por vezes, têm um foco principal em outras interpretações insuficientes ou errôneas. É o caso, por exemplo, da crítica realizada por Jacinto Coutinho, abaixo transcrita, que parece decorrer de outras interpretações errôneas, inclusive oriundas do STF.

\footnotetext{
É por isso que gente como Habermas tem tanto prestígio (algo para não espantar, portanto), mas Luhmann também (e seus derivados esdrúxulos e parvos - ou seria melhor dizer inseguros, recalcados, megalomaníacos? como Jakobs), o que é para espantar e endoidecer os mais lúcidos, que não brincam nem transigem sobre a CR. Para gente assim era preciso prisão em flagrante, como ironiza Lenio Luiz Streck, porque lesam cotidianamente a CR, em verdadeiros crimes de 'lesa-cidadania'. Há exceções (claro!), como sempre, mas não são muitos. (COUTINHO, 2007).
}

Nesse sentido, com o presente artigo, será possível notar que a teoria dos sistemas sociais autopoiéticos de Niklas Luhmann, em verdade, não é (ou não deveria ser) o alvo principal das críticas, mas a críticas deve ser sobre "um entendimento da teoria que foi formulado usando conceitos de um paradigma diferente" (KING, 2009, p. 66).

\section{METODOLOGIA}


Teoria dos sistemas autopoiéticos e constituição:

Luhmann e o Supremo Tribunal Federal

Para o presente trabalho, foram realizadas pesquisas de decisões proferidas pelo Supremo Tribunal Federal, utilizando-se os mecanismos de busca de jurisprudências no website do próprio tribunal mencionado. A pesquisa foi realizada no primeiro semestre de 2015, tendo as seguintes palavras como critérios em tal mecanismo de busca: "autopoiese" e "Luhmann".

Após analisar a pertinência das decisões, foram encontradas cinco decisões proferidas pelo STF, cuja fundamentação se sustenta na teoria dos sistemas sociais autopoiéticos de Niklas Luhmann, mesmo que brevemente.

Como se verá no desenvolver do artigo, existem decisões que se embasam em Luhmann para tratar dos seguintes temas: a relação entre Direito e Política, aa Democracia, o Procedimento e o Direito Global. Será que a fundamentação e o caso concreto das decisões se coadunam à teoria de Luhmann?

\subsection{Luhmann, Direito e Política}

2.1.1. No habeas corpus n. ${ }^{\circ}$ 111.480-RS, o Ministro Joaquim Barbosa do Supremo Tribunal Federal (STF) cita Niklas Luhmann para fundamentar o seu voto divergente e vencido. A decisão discutiu a (in)constitucionalidade da obrigatoriedade da fixação de regime prisional inicial fechado aos crimes hediondos e equiparados, nos termos do Lei n. ${ }^{\circ}$ 11.464/07 - que deu nova redação ao artigo $2^{\circ}$ da Lei n. ${ }^{\circ}$ 8.072/90.

O habeas corpus foi impetrado com o objetivo de que o paciente, condenado pela prática do crime de tráfico de entorpecente, tivesse como regime inicial o semiaberto com base no art. 33, $§ 2^{\circ}$, alínea "b”, do Código Penal.

Em decisão por maioria, o STF declarou incidentalmente a inconstitucionalidade do $\S 1^{\circ}$ do art. $2^{\circ}$ da lei dos crimes hediondos (8.072/90), de modo a rechaçar a obrigatoriedade de fixação do regime fechado pela prática de crimes hediondos ou equiparados. Assim, concedeu a ordem para alterar o regime inicial de cumprimento da pena privativa de liberdade para o regime semiaberto.

Entretanto, de modo breve, e sem uma precisa referência bibliográfica, Luhmann é citado no voto divergente do Ministro Joaquim Barbosa parar fundamentar a constitucionalidade da obrigatoriedade do regime inicial fechado para o crime de tráfico de entorpecentes. Nesse sentido,

Essa distinção das esferas de atuação jurisdicional e política (Poderes Executivo e Legislativo) é sempre sublinhada na Teoria do Direito, não só por Kelsen mas também por Luhmann, Habermas, Hart. 
Com efeito, o Ministro Joaquim Barbosa considerou que a obrigatoriedade do regime inicial fechado para os crimes hediondos e equiparados é questão de política criminal, a qual deve permanecer sob a esfera exclusiva de decisão dos parlamentares. Assim, assevera não ser função do Poder Judiciário analisar se a política criminal é boa ou ruim, sob pena de violação do princípio da separação de poderes e da democracia representativa.

Ainda, continuando em seu voto, assevera que o legislador estabelece os standards para a individualização da pena, cuja observância é, em princípio, obrigatória pelo órgão jurisdicional. É nesse passo que o Ministro do STF menciona Luhmann, de modo a fundamentar a tese de que há de se ter uma distinção das esferas de atuação jurisdicional e política (executivo e legislativo).

Com base nisso, o Ministro Joaquim Barbosa entendeu ser constitucional a imposição do regime inicial fechado para crimes de tráfico de drogas e demais hediondos, sendo vedadas apenas as penas previstas pelo art. $5^{\circ}$, XLVII da Constituição (pena de morte, perpétuas, de trabalho forçados, de banimento e cruéis). Tal voto foi vencido pela maioria do STF.

2.1.2. Ao analisar o tema em Luhmann, de pronto, nota-se que a diferenciação entre Política e Direito não implica o isolamento. O sistema autopoiético é autorreferente, incluindo a diferença sistema/entorno como parte do processo interno, razão por que se refere a si mesmo na distinção em face do entorno tanto na constituição de seus elementos como na constituição de suas operações fundamentais (RODRIGUEZ, ARNOLD, 2007).

Na matriz pragmático-sistêmica, o sistema autopoiético - que é autorreferencial - é clausurado (operativamente) e aberto (cognitivamente) ao mesmo tempo (paradoxo) (ROCHA, 2001). Sua clausura (fechamento) não significa isolamento, de tal modo que sua clausura operativa “(...) es más bien una condición de la posibilidad de apertura. Toda apertura parte de un estado cerrado (...)” (LUHMANN, 1991, p. 444). É dizer, quando se diz aberto, quer-se dizer aberto em um sentido fechado/clausurado ${ }^{6}$.

Portanto, no voto do Ministro Joaquim Barbosa, há uma interpretação errônea sobre os sistemas autopoiéticos com relação à sua clausura - que é, muitas vezes, incompreendida ${ }^{7}$.

Com efeito, embora, de fato, haja uma diferenciação entre o sistema da Política e o sistema do Direito, a sociedade desenvolveu uma relação horizontal entre eles. Tratase do acoplamento estrutural entre os sistemas autopoiéticos. O acoplamento estrutural 
Teoria dos sistemas autopoiéticos e constituição:

Luhmann e o Supremo Tribunal Federal

está em consonância com a autopoiese, de modo que se coloca de maneira ortogonal, horizontal à autopoiese do sistema, ou seja, possibilita que o sistema, de modo duradouro, transforme desordem (do entorno) em ordem de maneira altamente seletiva (LUHMANN, 2010a). Com isso, o sistema supõe determinadas características de seu entorno de maneira duradoura, confiando estruturalmente nele (LUHMANN, 2005a). O acoplamento estrutural possibilita uma irritação recíproca entre sistemas diversos (RODRIGUEZ, ARNOLD, 2007).

E é a Constituição o acoplamento estrutural entre Direito e Política. Com isso, Luhmann assevera que a Constituição possibilita soluções jurídicas aos problemas de autorreferência do sistema político e, por sua vez, soluções políticas aos problemas de autorreferência do sistema jurídico (LUHMANN, 2007a).

Assim, em oposição a um sentido de isolamento entre os sistemas jurídico e político lançados na decisão do STF, o acoplamento estrutural permite uma abertura seletiva entre o Direito e a Política que mantêm sua autopoiese própria: "Es obvio que la separación de los sistemas no excluye las intensas relaciones causales" (LUHMANN, 2005a, p. 488).

É, nesses termos, Luhmann:

Con relación a esto, la Constitución que conforma y determina el Estado asume un sentido diferente en ambos sistemas: para el sistema jurídico es una ley suprema, una ley fundamental; para el sistema político es un instrumento político en doble sentido de política instrumental - modificadora de situaciones - y de política simbólica - no modificadora de situaciones. (...) De este modo, es posible que se desarrollen separadamente el sentido jurídico y el sentido político de la Constitución, lo que se hace patente en un incremento de la irritación recíproca. [grifou-se] (LUHMANN, 2005a, p. 548-549).

Com o processo de evolução social, toma forma o Estado de Direito a partir da relação (acoplamento estrutural) entre o sistema da Política e o sistema do Direito: "El sistema político ofrece al sistema del derecho premisas para su toma de decisiones en la forma de leyes positivamente promulgadas. El sistema del derecho, a su vez, ofrece al sistema político la legalidad necesaria para que éste haga el uso del poder" (RODRIGUEZ, 2010, p. 28). Assim, o poder político subordina-se ao Direito e, ao mesmo tempo, tem o direito de modificar o Direito.

Além disso, com a Constituição como acoplamento estrutural, o sistema político autorreproduz-se com base no código primário poder superior/poder subordinado, melhor dito, governo/oposição (NAFARRATE, 2009); porém, o código jurídico (lícito/ilícito) ocupa o lugar de codificação secundária do sistema político: "La presencia de la 
codificación secundaria no conduce a que 'las preferencias poder y derecho, o ausencia de poder y no-derecho, sean encubiertas... Esto significa que la distinción poder/ausencia de poder y lícito/ilícito se remiten mutuamente" (NEVES, 2011, p. 208). Com essa codificação secundária jurídica, o sistema político pode manter sua clausura operativa diante de pressões particularistas ou de outros fatores de seu entorno (NEVES, 2011).

Adotando o código lícito/ilícito como seu código secundário, o sistema da Política permite acrescentar ao código poder superior/poder inferior a distinção entre poder legítimo/poder ilegítimo (CORSI; ESPOSITO; BARALDI, 2006).

Por um diminuto aspecto, a citação à Luhmann está, de certa forma, em consonância com a teoria de Luhmann, isso porque, efetivamente, não é função do Direito (nem do Judiciário) analisar se a política criminal é boa ou ruim. Na verdade, o sistema do Direito e o seu centro (Judiciário) observarão se as políticas criminais estão conforme o direito (lícitas) ou se não estão conforme o direito (ilícitas) ${ }^{8}$.

Diante disso, a teoria luhmanniana esclarece que cada sistema parcial da sociedade monopoliza para si uma função, possuindo, a seu turno, um entorno que é incompetente para tal função. "Para la ciencia su entorno es científicamente incompetente, pero no políticamente incompetente, ni económicamente incompetente, etc." (LUHMANN, 2007, p. 600).

Daí por que ao Direito não cabe analisar as políticas criminais em termos políticos (relação povo e seus representantes políticos, p.ex.). Porém, à evidência que cabe ao Direito observar as políticas criminais a partir de seu código binário, i.e., se elas são lícitas ou ilícitas. Aqui, o voto do Ministro Barbosa também parece não condizer com a teoria de Luhmann.

Por derradeiro, relevante apontar que Niklas Luhmann não pretendeu escrever uma Teoria do Direito, mas, sim, uma teoria da sociedade em que o Direito é mais um sistema parcial dela e no qual tal sistema não pode ter uma posição externa à sociedade: "Lo anterior quiere decir que si las ciencias sociales quieren describir adecuadamente la sociedad, deben también considerarse a sí mismas" (RODRIGUES; ARNOLD, 2007, p.126). Em outras palavras: um direito da sociedade.

\subsection{Luhmann e Democracia}

2.2.1. Outro julgado do STF que cita Luhmann é o recurso extraordinário 658.312-SC. Nesse julgado, discutiu-se sobre a recepção do art. 384 da Consolidação das Leis do Trabalho (CLT) pela Constituição Federal de 1988. Tal artigo prevê o intervalo 
Teoria dos sistemas autopoiéticos e constituição:

Luhmann e o Supremo Tribunal Federal

de 15 minutos para mulheres trabalhadoras antes da jornada extraordinária, o que implicaria o pagamento de horas extras relativas a esse período. $\mathrm{O}$ recorrente pretendia que fosse reconhecida a não recepção do artigo mencionado, arguindo haver ofensa ao princípio da isonomia por haver uma diferenciação apenas em razão do sexo.

O recurso extraordinário foi improvido pelo STF, de maneira a reconhecer que o art. 384 da CLT foi recepcionado pela Constituição Federal de 1988. O Min. Dias Toffoli, em seu voto como relator, apontou que a Constituição Federal de 1988 utilizou alguns critérios para um tratamento diferenciado entre homens e mulheres.

Esses parâmetros constitucionais são legitimadores de um tratamento diferenciado, desde que tal tratamento sirva para ampliar os direitos fundamentais sociais e que se observe a proporcionalidade na compensação das diferenças. Nesse ponto, o Min. Toffoli ressaltou que o discrímen, na espécie, não viola a universalidade dos direitos do homem, pois o legislador vislumbrou a necessidade de maior proteção ao grupo de trabalhadores do gênero feminino de forma justificada e proporcional.

Ao fim de seu voto, o Ministro Relator assevera que, ainda que existisse dúvida - embora faça questão de registrar que ele não há tem -, caberia a invocação do "forema" in dubio pro legislatore em defesa da própria democracia, no sentido de considerar constitucional uma lei quando há zona de penumbra com relação à constitucionalidade ou não de uma decisão discricionária adotada pelo legislador. É aqui que o Min. Dias Toffoli faz menção a Peter Häberle - o qual, segundo mencionado no voto, se apoia em Niklas Luhmann:

Da mesma forma, quando se vislumbra, pela abertura constitucional, uma pluralidade de concretizações possíveis, há que se respeitar o 'pensamento possibilista', há muito defendido por Peter Häberle, apoiado no escólio de Niklas Luhmann (Komplexität und Demokratie, PSV, 4, 1968, P. 494 e ss.), na defesa da própria democracia, desde que, como bem anotou aquele filósofo e jurista, as alternativas surjam dos marcos constitucionais (HÄBERLE, 2002, p. 68).

Vê-se, pois, que a referência à Luhmann se dá com o fito de fundamentar a defesa da democracia mediante o respeito à legislação trabalhista no caso, tendo em vista uma pluralidade de concretizações possíveis e o pensamento possibilista de Peter Häberle. E, assim, o STF decidiu que o art. 381 da CLT foi recepcionado pela Constituição Federal de 1988, não provendo o recurso extraordinário. 
2.2.2. Ao tratar do sistema da Política, Luhmann aponta que a sua função consiste na capacidade de impor decisões coletivamente vinculantes ${ }^{9}$. O núcleo da Política é o problema do poder na sociedade (RODRIGUEZ; ARNOLD, 2007).

$\mathrm{O}$ poder é um meio de comunicação simbolicamente generalizado (LUHMANN, 2005c). Os meios de comunicação simbolicamente generalizados têm a função de aumentar a probabilidade de aceitação de uma comunicação; é, por exemplo, o caso de ego aceitar a ordem de alter de pagar uma multa porque alter detém o poder (CORSI; ESPOSITO; BARALDI, 2006). Em outros termos, trata-se da obediência. Por isso, Luhmann conclui que a força física anula o poder (LUHMANN, 2005c).

As sanções são ameaças à desobediência. Contudo, ao ser desobedecido, o uso da força física revela uma ausência de poder. Por conseguinte, para que o poder se conserve, o exercício da força física deve permanecer uma alternativa a ser evitada (CORSI; ESPOSITO; BARALDI, 2006).

Daí por que o poder é maior à medida que há mais possibilidades de seleção para ego frente à ordem de alter, e, apesar disso, a ordem é obedecida (LUHMANN, 2005c). Assim como a Constituição, a democracia é uma aquisição evolutiva da sociedade, ou seja, um mecanismo social que, ao reduzir a complexidade, termina aumentado-a $^{10}$ (paradoxo), no sentido de possibilitar um acesso mais variado a possibilidades que não existiriam senão por tal aquisição evolutiva ${ }^{11}$. Por isso, na democracia, o poder é considerado maior, já que obtém obediência com maior liberdade de escolhas.

Com a democracia, o próprio sistema da Política desenvolveu uma recodificação do código poder superior/poder inferior para o código governo/oposição (NAFARRATE, 2009; LUHMANN, 2002). Embora não governem ambos, a decisão política refere-se tanto ao governo quanto à oposição, no sentido de fazer destaque à contingência da decisão ${ }^{12}$. É dizer, há alternativas, uma vez que existe a possibilidade de substituir quem governa. Isso se dá devido a uma diferença temporal proporcionada pelas eleições: "la posibilidad de que los partidos en el gobierno y en la oposición cambien sus puestos en las elecciones" (LUHMANN, 2002, p. 164.). Além disso, mesmo não tendo poder, a oposição faz valer o poder dos não poderosos, ao opor-se ao governo. Assim ensina Luhmann:

En lugar de ello, propongo concebir la democracia como la escisión de la cima: la escisión de la cima del sistema político diferenciado mediante la distinción entre gobierno y oposición. En terminología de teoría de sistemas puede hablarse también del código del sistema político, no entendiendo por 
Teoria dos sistemas autopoiéticos e constituição:

Luhmann e o Supremo Tribunal Federal

código sino el hecho de que el sistema se orienta a partir de una diferencia entre valor positivo y negativo: (...) y, en el sistema político, precisamente la diferencia entre gobierno/oposición.

Este código consigue disolver una paradoja fundamental que aparece en todos los sistemas con diferencias de poder organizadas. (...) La diferenciación entre gobierno y oposición consiguió encontrar una forma que, por así decir, desparadojizó el problema. La oposición no tiene ningún poder de gobierno, pero precisamente por ello puede hacer valer el poder de los no poderosos. (LUHMANN, 2002, p. 162-163).

Diante disso, na teoria luhmanniana, ao analisar a democracia, não é possível verificar que, necessariamente, há fundamento para reconhecer a constitucionalidade/inconstitucionalidade da legislação trabalhista, ainda que não esteja equivocada a menção indireta de que, na democracia, há maior complexidade (possibilidades).

Entretanto, em Luhmann, a democracia não implica um in dubio pro legislatore. E, ademais, como já explanado, ao Judiciário cabe decidir sobre o que é conforme o direito (lícito) e o que não é conforme o direito (ilícito).

Com relação à legislação e ao Judiciário, Luhmann assevera que o sistema do Direito se diferencia internamente em centro/periferia. É uma concepção heterarquizada, isto é, não há uma ordem hierárquica entre centro/periferia (CLAM, 2005; LUHMANN, 1990). No Direito, é a legislação que ocupa a periferia, situada na fronteira com o sistema Político; sua função é a de acomodação ou filtragem da irritação do sistema Político e que irradia no sistema jurídico. E o Judiciário (Tribunais, juízes) ocupa a posição central no sistema do Direito, cujas operações só reproduzem operações filtradas - e não filtrantes -, colocando em prática o código (lícito/ilícito) e os programas (leis) jurídicos, fazendo uso reservado do símbolo circundante da validade jurídica (CLAM, 2005; LUHMANN, 1990).

Disso não decorre a conclusão de que o Judiciário, na dúvida, deve considerar lícita determinada lei (in dubio pro legislatore) conforme faz parecer na citação realizada na decisão do STF.

\subsection{Luhmann e Procedimento}

2.3.1. Na arguição de descumprimento de preceito fundamental (ADPF) n. ${ }^{\circ}$ 144-DF, o Min. Ricardo Lewandowski do STF citou a obra Legitimação pelo procedimento de Niklas Luhmann ${ }^{13}$. Essa ADPF teve como objeto a não recepção ${ }^{14}$ de parte das alíneas $d, e, g$ e $h$ do inciso I do art. $1^{\circ}$ e a não recepção do art. 15 , todos da Lei Complementar n. ${ }^{\circ} 64 / 90$, conforme previsão legal à época ${ }^{15}$, especificamente no ponto 
em que exige, para efeito de reconhecimento da inelegibilidade, o trânsito em julgado de determinadas decisões.

Igualmente, a ADPF questionou a interpretação veiculada - embora não impugnasse expressamente - na súmula $13^{a}$ do Tribunal Superior Eleitoral (TSE), que decorreu de sucessivas decisões daquele Tribunal Superior no sentido de não reconhecer a autoaplicabilidade do $\$ 9^{\circ}$ do art. 14 da Constituição Federal. E, assim, o arguente requereu que os juízos eleitorais realizassem o exame da vida pregressa dos candidatos a cargos eletivos, sem se limitar aos casos previstos em lei.

O STF julgou improcedente a acima mencionada ADPF. Sob um aspecto, reconheceu a não autoaplicabilidade do $\$ 9^{\circ}$ do art. 14 da CF/88 na redação da EC n. ${ }^{\circ}$ 04/94, porquanto o Judiciário não pode, sem ofensa ao princípio da divisão funcional do poder, substituir-se ao legislador, para definir, por critérios próprios, os casos em que a vida pregressa do candidato implicar inelegibilidade, quando da ausência de lei complementar exigida pelo dispositivo constitucional.

Ainda, o STF decidiu ${ }^{16}$ que a presunção constitucional de inocência aplicável expressivamente no processo penal - tem eficácia irradiante, de modo a estender-se a presunção de inocência ao âmbito do processo eleitoral. Portanto, a inelegibilidade somente pode ser configurada por sentença penal condenatória transitada em julgado ${ }^{17}$.

Ao tratar da não autoaplicabilidade do $\S 9^{\circ}$ do art. 14 da $\mathrm{CF} / 88$, o voto do Ministro Lewandowski afirmou que, do contrário, haveria uma verdadeira norma em branco, permitindo aos juízes eleitorais determinarem a inelegibilidade de certo candidato com base em uma avaliação claramente subjetiva daquilo que a Constituição denomina de vida pregressa, a fim de proteger, segundo o alvedrio de cada julgador, a probidade administrativa e a moralidade para o exercício do mandato. É nesse ponto que o Min. Lewandowski cita Niklas Luhmann:

Lembro, nesse passo, que Niklas Luhmann, em conhecida passagem de uma
de suas mais importantes obras, assentou que a única forma de se ver o sistema
social liberado dos constrangimentos e da aleatoriedade daquilo que
denominou de 'mercado político' de crescente complexidade é a
institucionalização de procedimentos decisórios institucionalizados de uma
maneira a alcançar-se, em suas palavras, a legitimação pelo procedimento.

Com isso, o Ministro Lewandowski pretendeu fundamentar que o devido processo eleitoral, que compreende, entre outras, regras permanentes e objetivas acerca da inelegibilidade, configura precisamente um importante mecanismo institucional 
Teoria dos sistemas autopoiéticos e constituição:

Luhmann e o Supremo Tribunal Federal

destinado a conferir legitimidade à seleção e eleição dos candidatos. E, portanto, conclui que o critério do trânsito em julgado de sentença condenatória não pode ser modificado por mera interpretação judicial, sob pena de indevida invasão da seara legislativa por parte dos magistrados.

Niklas Luhmann também é citado na ADI n. 3.741-DF, novamente, pelo Ministro Ricardo Lewandowski. O objeto da ação constitucional de controle abstrato era o de que fosse declarada a inconstitucionalidade da totalidade da Lei n. ${ }^{\circ} 11.300 / 06$, que dispõe sobre propaganda, financiamento e prestação de contas das despesas com campanhas eleitorais, haja vista a afronta à anterioridade eleitoral (art. 16, CF/88), nos termos do requerente.

No seu voto, o Ministro Lewandowski aponta que a questão objeto da demanda revela a tensão existente entre, de um lado, os interesses político-partidários e, de outro, a necessidade vital para a convivência democrática da existência de regras universais, objetivas e transparentes, orientadoras de um embate eleitoral isento de distorções, que permitam que todos os interessados possam participar de forma justa e equilibrada.

$\mathrm{Na}$ sequência, com base em Norberto Bobbio, o seu voto ressalta que o conceito de democracia como predomínio da vontade da maioria não pode ser dissociado da definição de democracia como via, método, conjunto de regras do jogo que estabelecem como devem ser tomadas as decisões coletivas. Nesse passo, o Min. Lewandowski faz referência a Luhmann.

Niklas Luhmann, estudando a importância dos ritos formais para a estabilidade das instituições, desenvolveu a sua conhecida teoria da 'legitimação pelo procedimento', compreendido este como um sistema de ação capaz de produzir decisões antecipadamente aceitas por todos os integrantes de um dado grupo social, independentemente de seu desfecho.

Fundamenta-se em Luhmann para sustentar que o processo eleitoral, em uma democracia, deriva sua legitimidade de um conjunto de procedimentos, aperfeiçoados de tempos em tempos, que se destinam a evitar, o tanto quanto possível, a ocorrência de deformações e desequilíbrios, conferindo a mais ampla credibilidade ao seu resultado final. Por isso, o Ministro Lewandowski faz menção à obra Legitimação pelo procedimento de Niklas Luhmann, no sentido de que o procedimento é capaz de produzir decisões antecipadamente aceitas por todos os integrantes de um dado grupo social. 
Julgando parcialmente procedente $^{18}$, o STF decidiu que a Lei n. ${ }^{\circ} 11.300 / 06$ não inovou no tocante a normas relativas ao processo eleitoral, visto que - não se alterando a disciplina das convenções partidárias, os coeficientes eleitorais tampouco a extensão do sufrágio universal - não houve o rompimento da igualdade de participação dos partidos políticos e dos respectivos candidatos no processo eleitoral; não introduziu deformação de modo a alterar a normalidade das eleições; inexistiu alteração motivada por propósito casuístico.

Com efeito, reconheceu tratar-se de normas de caráter eminentemente procedimental, com vistas a conferir mais autenticidade à relação entre partidos políticos e seus candidatos e a dar maior transparência ao modo com que os primeiros obtêm e empregam os seus recursos.

2.3.2. O livro Legitimação pelo Procedimento foi escrito por Luhmann em sua denominada fase pré-autopoiética ${ }^{19}$. Ao analisar a sua teoria em sua fase autopoiética, é possível notar que o procedimento resulta da capacidade de autoorganização ${ }^{20}$ dos sistemas parciais da sociedade (como o Direito e a Política) ${ }^{21}$. Assim, como já foi dito alhures, os sistemas parciais da sociedade criam seus próprios códigos binários e programas (LUHMANN, 2005b) além de seus procedimentos, ou seja, criam suas próprias estruturas.

A ideia de legitimação pelo procedimento pode implicar a errônea intepretação reducionista que considera conservador ou decisionista a teoria de Luhmann $^{22}$. Diferentemente do mencionado na decisão do STF, não são as decisões que são antecipadamente aceitas, e sim os procedimentos que levam a elas.

Os procedimentos, primeiramente, cumprem a função de reduzir o número ilimitado de formas possíveis de comportamento, sem que causem discussões prévias sobre o seu sentido e sua finalidade (LUHMANN, 1980). Todas as comunicações realizadas no processo são consideradas “informações que abrem, multiplicam ou eliminam possibilidades, que definem os figurantes e o seu passado relevante e que tornam mais estreito o espaço de manobra da decisão" (LUHMANN, 1980, p. 41).

Ao produzir um passado próprio, todo processo realiza uma história própria que reduz ainda mais a complexidade, isso porque, à medida que o processo se desenrola, reduzem-se as possibilidades de atuação dos participantes (LUHMANN, 1980). Com isso, o procedimento realiza uma separação de papéis, de maneira que cada participante (advogados, juízes, entre outro) tem de desempenhar um papel que compromete e vincula as expectativas com relação a seus comportamentos (LUHMANN, 1980). 
Teoria dos sistemas autopoiéticos e constituição:

Luhmann e o Supremo Tribunal Federal

Um ponto essencial do procedimento é que ele não antecipa o conteúdo da decisão, diferentemente do explicitado pelo STF. Em verdade, com o procedimento, há a certeza de que será tomada uma decisão, mas há a incerteza quanto à natureza (resultado) da decisão. E, assim, Luhmann destaca que essa certeza e incerteza proporcionadas pelo procedimento induzem os seus participantes a cooperarem com o processo, porquanto a incerteza quanto ao resultado da decisão incentiva os participantes a contribuírem para o progresso do procedimento, de modo a motivá-los à aceitação de seu papel e à absorção gradual da incerteza da decisão. Nesses termos, assinala Luhmann:

Todos os outros participantes têm de ser induzidos através do próprio sistema específico do processo jurídico a uma cooperação justificativa da causa. Para isso são essenciais os seguintes componentes: um interesse próprio pelo assunto; a certeza de que será tomada uma decisão; e a incerteza quanto à natureza desta. É sobretudo a incerteza quanto ao resultado que é essencial ao procedimento. Dá aos participantes o incentivo de contribuir para o progresso do procedimento por meio das suas próprias tentativas de redução, mantémlhes vivas as esperanças e conduzi-los através do caminho que, de acordo com as regras do processo jurídico, levará à decisão. Por outras palavras, a incerteza motiva a aceitação dum papel e conjuntamente também da relação desse papel, que absorver gradualmente a incerteza (LUHMANN, 1980, p. 45-46).

O fato de o procedimento não garantir o conteúdo da decisão não implica que o Direito seja decisionista ou conservador. Como já explanado, o sistema do Direito é clausurado normativamente e aberto cognitivamente ao mesmo tempo. Ora, as normas jurídicas (programas) possibilitam uma abertura condicional, e seu código binário lícito/ilícito realiza uma conexão entre comunicações - excluindo comunicações terceiras.

Isso quer dizer que o Direito é aberto ao seu entorno, mas processa as irritações a partir de sua própria compreensão produtiva ${ }^{23}$. E o Judiciário também é relevante nesse viés. O Judiciário (tribunais e juízes) possui uma abertura (aprendizado), porém diferente da periferia (legislação). Com efeito, a obrigatoriedade de decidir do Judiciário $^{24}$ importa em que, por um lado, o sistema jurídico constrange o Judiciário a decidir com base em seu fechamento operacional e, por outro lado, garante a abertura do sistema jurídico a uma infindável série de demandas do entorno, revelando que o Judiciário é um inevitável intérprete do Direito (CAMPILONGO, 2002). Com isso, a obrigatoriedade de decidir gera um paradoxo: "transforma a coação (proibição da denegação de Justiça) em liberdade (formulação de um direito judicial); o fechamento (completude do ordenamento) em abertura (o Judiciário deve responder a todas as demandas)" (CAMPILONGO, 2002, p.35). Assim sendo, é na própria obrigatoriedade de 
decidir casos específicos previstos em leis gerais que o Judiciário aprende a partir de casos-problemas $^{25}$.

E, no mesmo sentido do procedimento jurídico, o sistema da Política possui como procedimento as eleições políticas, nas quais se criam papéis (eleitor, candidato, entre outros), que são limitados nas suas possibilidades de comportamento por meio de normas jurídicas. Ainda, a incerteza do resultado da eleição serve como motivo essencial para a colaboração, a comunicativa e o seu compromisso ${ }^{26}$.

\subsection{Luhmann, Teubner e Autopoiese}

2.4.1. Por fim, no julgamento da ADI n. ${ }^{\circ}$ 2.937-DF, o Ministro Gilmar Mendes proferiu voto referindo-se à autopoiese, citando Günther Teubner. A ADI tinha como objeto a declaração de inconstitucional de determinados dispositivos do Estatuto de Defesa do Torcedor (Lei n. $\left.{ }^{\circ} 10.671 / 03\right)$.

O STF julgou improcedente, mantendo incólume o Estatuto de Defesa do Torcedor. O plenário do STF decidiu tratar-se de norma de caráter geral, que impõe limitações válidas à autonomia relativa das entidades de desporto, sem lesionar direitos e garantias individuais.

E, ao analisar o caráter geral do Estatuto do Torcedor em seu voto, o Ministro Gilmar Ferreira Mendes menciona o conceito da autopoiese com base em Günther Teubner:

\footnotetext{
O notável Gunther Teubner, por exemplo, fala que aqui [referindo-se às regras da área do desporto e sua autonomia] é um campo em que a autopoiese se realiza de maneira muito forte, muito evidente, citando como exemplo o poder da FIFA; quer dizer, consegue conglomerar um número elevado de países, federações que a compõem, muito mais até do que a ONU, estabelece regras mais ou menos uniformes e tem um poder coativo enorme. [grifou-se]
}

Com efeito, o Ministro Gilmar Mendes assevera que, por vezes, a imposição de uma regulação de uma disciplina universal decorre da necessidade de um tratamento uniforme; e, em razão disso, há necessidade de que haja a definição de responsabilidade de forma geral e global. Assim, em se tratando de um campeonato nacional, não se faz viável a existência de disciplinas diversas sobre a temática relativa ao chamado Direito do Consumidor, expectador, e as responsabilidades dos eventuais apresentadores, prestadores. A propósito, como menciona, ao citar Günther Teubner, o Direito Desportivo consegue estabelecer regrais mais ou menos uniformes de caráter coativo em grande parte do mundo. 
Teoria dos sistemas autopoiéticos e constituição:

Luhmann e o Supremo Tribunal Federal

2.4.2. Primeiramente, impõe esclarecer que Teubner diverge do conceito de autopoiese de Luhmann. Teubner defende uma autopoiese gradativa para o Direito (SCHWARTZ, 2007b). Trata-se da necessidade do hiperciclo. Para o hiperciclo e a autonomização do Direito, deve haver uma articulação entre a determinação autorreferencial dos seus componentes (autoobservação), a incorporação e a utilização operativa no sistema dessa auto-observação (autoconstituição) e, finalmente, a articulação hipercíclica dos componentes sistêmicos autogerados, enquanto elementos que se reproduzem circularmente (autorreprodução) (TEUBNER, 1993).

Para Luhmann, o sistema não pode ser mais ou menos autopoiético, não admitindo nenhuma graduação (LUHMANN, 2010b). Assim, ou o Direito reproduz-se por si mesmo ou não; e, nas sociedades atuais, o Direito reproduz-se (KING, 2009). Como dito, a autopoiese não significa que um sistema não possa manter contato com o entorno, mas o mantém a partir de sua clausura operativa: "não pode se comunicar com o ambiente [entorno], mas deve obrigatoriamente se comunicar acerca do ambiente [entorno]" (KING, 2009, p. 86). Aliás, exemplo disso é a Constituição, que mantém uma irritação recíproca entre Direito e Política. É dizer, o Direito observará a sua abertura em termos jurídicos, de modo a observar juridicamente questões políticas, econômicas, entre outras.

$\mathrm{Na}$ citação à Luhmann, há certa referência a um Direito Global. A teoria luhmanniana já havia lançado tal previsão ${ }^{27}$, de tal modo que, na atual sociedade, o Direito não se identifica tão só na forma de Estados. Há, em verdade, um sistema jurídico global, que conta com uma multiplicidade de contradições internas (FISCHER-LESCANO; TEUBNER, 2004) (fragmentação).

Diante disso, Teubner assevera que o código jurídico não é privativo do Direito estatal, muito embora o Direito Global apresente características significativamente diferentes daquele: (i) as suas fronteiras são formadas por invisíveis mercados, invisíveis comunidades profissionais, invisível network social; (ii) as suas fontes jurídicas não se referem ao processo legislativo em geral, o Direito Global é produzido no processo autoorganizado de acoplamentos estruturais; (iii) e, no Direito Global, a unidade jurídica constitui uma ameaça à sua cultura, de tal maneira que ele deve resolver problemas de como garantir uma suficiente variedade de fontes jurídicas (TEUBNER, 1997b).

Trata-se de um Direito sem o Estado (Global Law without a State). São denominadas de constituições civis transnacionais (TEUBNER, 2004; 2005), onde se desenvolve um Direito primariamente por atores privados ou quase públicos, ou seja, sem 
o Estado. Como exemplo, têm-se a lex mercatoria, a lex digitalis e a lex sportiva. A FIFA é um exemplo de lex sportiva.

A proposta de Teubner é a de que as várias Constituições sem Estado (civis) constituam acoplamentos estruturais entre o Direito e os demais subsistemas da sociedade, e não só entre a Política (SCHWARTZ, 2007b). E nesses termos, Teubner assevera:

\begin{abstract}
If, in seeking to illuminate the blind-spot, one abandons the state-centring of the constitution, then the real possibilities of constitutionalisation without the state become visible. For constitutional theorists, this amounts to breaking a taboo. For them, a constitution without a state is, at best, a utopia, and a poor one into the bargain. But this formula is definitely not an abstract normative demand for remote, uncertain futures, but an assertion of a real trend that can be observed on a world-wide scale today. The thesis is: the emergence of a multiplicity of civil constitutions. The constitution of world society does not come about exclusively in the representative institutions of international politics, nor can it take place in a unitary global constitution which overlies all areas of society, but, instead, emerges incrementally in the constitutionalisation of a multiplicity of autonomous sub-systems of world society. [grifou-se]
\end{abstract}

Ocorre que Teubner deixa claro que, diante de uma mutiplicidade de Constituições civis, é necessária a releitura dos parâmetros constitucionais, sustentada em uma constatação tríplice (TEUBNER, 2004).

O (i) dilema da racionalização expõe a necessidade de construir instituições de um "societal constitutionalism", no sentido de que legitimar a autonomia de sujeitos privados na deliberação democrática além das instituições políticas ${ }^{28}$. A (ii) globalização policêntrica pode ser reconhecida como a ausência de um centro único na sociedade que possa regular/resolver todos os problemas, e, assim é o caso do Direito com várias Constituições civis, onde cada qual possui sua autonomização ${ }^{29}$. Por fim, (iii) o creeping constitutionalization traz a pergunta inicial sobre se, atualmente, o sistema jurídico sequer teria condições de ter uma Constituição como acoplamento estrutural, como é visto em países periféricos ${ }^{30}$. Trata-se de uma crítica às Constituições ${ }^{31}$.

De todo modo, cumpre frisar que, com base no transconstitucionalismo de Marcelo Neves ${ }^{32}$, nota-se ser necessária uma reconstrução do sentido do entorno, mesmo quando se trata de uma relação entre uma ordem jurídica estatal e uma ordem jurídica transnacional: “(...) que envolve uma certa desconstrução do outro e uma autodesconstrução: tanto de conteúdo do 'outro' são desarticulados (falsificados!) e rearticulados internamente, quanto conteúdos de sentido originários da própria ordem são 
Teoria dos sistemas autopoiéticos e constituição:

Luhmann e o Supremo Tribunal Federal

desarticulados (falsificados!) e rearticulados em face da introdução do 'outro"” (NEVES, 2003, p. 118).

\title{
3. CONCLUSÃO
}

Nos termos do presente artigo, foi possível verificar algumas interpretações errôneas e outras interpretações insuficientes com pouca clareza acerca da teoria de Niklas Luhmann. Não se trata de criticar as decisões judiciais, até mesmo porque se reconhece não sendo a função do Judiciário a busca pela verdade acadêmica.

O presente artigo pretendeu esclarecer conceitos da teoria luhmanniana por vezes interpretados equivocadamente, os quais, por sua vez, geram uma crítica equivocada e sumária por outros autores.

À evidência, não se olvida de que a teoria de Luhmann seja deveras complexa, mas tal complexidade é correspondente à supercomplexidade da sociedade atual. A propósito, Jean Clam já admitiu que a teoria dos sistemas sociais autopoiéticos de Niklas Luhmann traz inúmeras dificuldades de compreensão, porém, em contraposição, a teoria tem a capacidade de aclarar fatos sociais como relâmpagos.

\begin{abstract}
A teoria sistêmica de Niklas Luhmann faz exigências quase impossíveis de se cumprir no que se refere à sua própria recepção. Frequentemente, a despeito de um longo enfronhar-se na sua leitura, ela continua infrutífera. Até mesmo os mais esforçados e os iniciados não estão muito certos de terem captado corretamente as abstrações com que a teoria lida incessantemente. Tem-se a impressão de andar em círculos por um espaço enevoado, no qual, entretanto, seguidamente fulguram faíscas que o aclaram como relâmpagos (CLAM, 2006, p. 09).
\end{abstract}

Assim, o conselho do próprio Luhmann a uma estudante - relatado por Michael King - é o melhor conselho que se pode dar aos que queiram enfrentar e criticar teorias científicas. É o de enfrentá-las e criticá-las cientificamente: “isto é, para repetir o conselho de Luhmann a uma estudante americana: 'Leia mais"” (KING, 2009, p. 75).

Em conjunto com o esclarecido por Jean Clam, ler mais para que se deparem com a compreensão dos fatos sociais como relâmpagos: "É essa sempre inesperada aclaração de nexos complexos que afasta a frustração e fortalece a convicção de que, por trás do que não se logrou captar claramente, se ocultam as chances intuídas de uma noção mais elevada" (CLAM, 2006, p. 9).

\section{REFERÊNCIAS}


BRASIL. Supremo Tribunal Federal. Ação Direta de Inconstitucionalidade n. ${ }^{0}$ 3.714DF. Relator: Lewandowski, Ricardo. Julgado em 06.08.2006. Publicado no DJ em 23.02.2007.

BRASIL. Supremo Tribunal Federal. Arguição de Descumprimento de Preceito Fundamental n. ${ }^{\circ}$ 144-DF. Relator: De Mello, Celso. Julgado em 06.08.2008. Publicado no DJ em 25.02.2010.

BRASIL. Supremo Tribunal Federal. Ação Direta de Inconstitucionalidade n. ${ }^{\circ}$ 2937DF. Relator: Peluso, Cezar. Julgado em 23.02.2012. Publicado no DJ em 28.05.2012.

BRASIL. Supremo Tribunal Federal. Habeas Corpus n. ${ }^{\circ}$ 111.480-RS. Relator: Fux, Luiz. Julgado em 29.05.2012. Publicado no DJ em 19.06.2012.

BRASIL. Supremo Tribunal Federal. Recurso Extraordinário n. ${ }^{\circ}$ 658.312-SC. Relator: Toffoli, Dias. Julgado em 27.11.2014. Publicado no DJ em 09.02.2015.

CAMPILONGO, Celso. Política, Sistema Jurídico e Decisão Judicial. São Paulo: Max Limonad, 2002.

CORSI, Giancarlo; ESPOSITO, Elena; BARALDI, Cláudio. Glosario sobre la teoría Social de Niklas Luhmann. México: Universidad Iberoamericana, 2006.

COUTINHO, Jacinto Nelson de Miranda. Apresentação. In: BOCKELMANN, Paul; VOLK, Klaus. Direito penal: parte geral. Rio de Janeiro: Del Rey, 2007.

CLAIM, Jean. Questões fundamentais de uma teoria da sociedade - contingência, paradoxo e só-efetuação. São Leopoldo: Editora Unisinos, 2006.

A Autopoiese no Direito. In: ROCHA; Leonel Severo; SCHWARTZ, Germano; CLAM, Jean. Introdução à Teoria do Sistema Autopoiético do Direito. Porto Alegre: Livraria do Advogado, 2005, p. 87-145.

FEBBRAJO, Alberto; CORSI, Giancarlo. Sociology of Constitutions: A Paradoxical Perspective. Farnhamn: Ashgate, 2015.

FISCHER-LESCANO, Andreas; TEUBNER, Gunther. Regime-Collisions: the vain search for legal unity in the fragmentation of global Law. In: Michigan Journal of International Law. Vol. 25, 2004.

KING, Michael. A verdade sobre a autopoiese no direito. In: ROCHA; Leonel Severo; KING, Michael; SCHWARTZ, Germano. A verdade sobre a autopoiese no direito. Porto Alegre: Livraria do Advogado, 2009, p. 41-97.

LUHMANN, Niklas. Legitimação pelo Procedimento. Brasília: Universidade de Brasília, 1980.

Sociologia do Direito I. Rio de Janeiro: Tempo Brasileiro, 1983. 
Teoria dos sistemas autopoiéticos e constituição:

Luhmann e o Supremo Tribunal Federal

A posição dos Tribunais no sistema jurídico. Revista Ajuris, n. ${ }^{\circ}$ 49, Porto Alegre, 1990, p. 149-168.

. Sistemas Sociales: lineamientos para una teoría general. $1^{\mathrm{a}}$ ed. México:

Alianza Editorial/Universidad Iberoamericana, 1991.

Teoría política en el Estado de Bienestar. Madrid: Alianza Editorial, 2002.

El derecho de la sociedad. México: Herder, 2005a.

El arte de la sociedad. México: Herder, 2005b.

Poder. México: Universidad Iberoamericana, 2005c.

. Sociología del Riesgo. México: Universidad Iberoamericana, 2006.

La Sociedad de la Sociedad. México: Herder, 2007.

Introdução à Teoria dos Sistemas. 2a ed. Petrópolis: Vozes, 2010a.

Organización y decisión. México: Universidad Iberoamericana, 2010 b.

NEVES, Marcelo. Los Estados en el centro y los Estados en la periferia: algunos problemas con la concepción de Estados de la sociedad mundial en Niklas Luhman $n$. In: NAFARRATE, Javier Torres; RODRÍGUEZ, Darío Mansilla (ed.). Niklas Luhmann: La Sociedad como Pasión: aportes a la teoría de la sociedad de Niklas Luhmann. México: Universidad Iberoamericana, 2011.

Entre Têmis e Leviatã: uma relação difícil. São Paulo: Martins Fontes, 2008.

Transconstitucionalismo. São Paulo: Editorial WMF Martins Fontes, 2013 b.

PRIBÁN, Jirí. A questão da soberania no pluralismo jurídico global. In: SCHWARTZ, Germano; PRIBÁN, Jirí; ROCHA, Leonel Severo. Sociologia Sistêmico-autopoiética das Constituições. Porto Alegre: Livraria do Advogado. 2015, p. 83-136.

ROCHA, Leonel Severo. O direito na forma de sociedade globalizada. In: ROCHA, Leonel Severo; STRECK, Lênio Luiz (orgs.). Anuário do Programa de Pósgraduação em Direito. São Leopoldo: Editora Unisinos, 2001, p. 117-137.

RODRÍGUEZ, Darío Mansilla; ARNOLD, Marcelo. Sociedad y teoría de sistemas: Elementos para la compresión de la teoría de Niklas Luhmann. Santiago de Chile: Editorial Universitaria, 2007.

RODRÍGUEZ, Darío Mansilla. Los Límites del Estado en la Sociedad Mundial: de la Política al Derecho. In: NEVES, Marcelo (coord.). Transnacionalidade do Direito: novas perspectivas dos conflitos entre ordens jurídicas. São Paulo: Quartier Latin, 2010, p. 25-52. 
SCHWARTZ, Germano. A fase pré-autopoiética do sistemismo Luhmanniano. In: ROCHA, Leonel Severo; SCHWARTZ, Germano; CLAM, Jean. Introdução à Teoria do Sistema Autopoiético do Direito. Porto Alegre: Livraria do Advogado, 2005.

. A Autopoiese dos Direitos Fundamentais. In: MACEDO, Elaine Harzheim; OHLWEILER, Leonel Pires; STEINMETZ, Wilson (orgs.). Direitos Fundamentais. Canoas: Editora, 2007a, p. 41-56.

Constituições Civis e Regulação: Autopoiese e Teoria Constitucional. In: Conpedi - XVI Encontro Preparatório para o Congresso Nacional, 2007, Campos do Goytacazes. Anais do XV Encontro Preparatório para o Congresso Nacional do Conpedi, Florianópolis: Fundação Boiteux, 2007b. Disponível em:

$<$ http://www.conpedi.org.br/manaus/arquivos/anais/campos/germano_andre_schwartz.p df $>$. Acesso em: 21/07/2014.

TEUBNER, Gunther. O Direito como Sistema Autopoiético. Lisboa: Fundação Calouste Gulbenkian, 1993.

Breaking Frames: the global interplay of legal and social systems. In: The American Journal of Comparative Law. Vol XLV, 1997a.

Global Bukowina: legal pluralism in the world society. In:

TEUBNER, Gunther (org.). Global Law without a State. Brookfield: Dartmouth, 1997b, p. 03-28.

. Societal Constitutionalism: Alternatives to State-Centred

Constitutional Theory? In: JOERGES, Christian; SAND, Inger-Johanne; TEUBNER, Gunther. Transnational Governance and Constitutionalism. USA: Hart Publishing, 2004, p. 03-28.

Direito, Sistema e Policontexturalidade. Piracicaba: Editora

UNIMEP, 2005.

WEBBER, Suelen da Silva. Decisão, Risco e Saúde: o paradoxo da decisão judicial frente a pedidos de medicamentos experimentais. Curitiba: Juruá, 2013.

Artigo recebido em 31 de agosto de 2016 e aceito em 09 de dezembro de 2017

\footnotetext{
${ }^{1} \mathrm{O}$ presente artigo é resultante de projeto de pesquisa financiado pelo CNPq (P. 306131/2014-5).

${ }^{2}$ El famoso postulado de la falsabilidad (Popper) dice: la tesis de la verdad son sólo relevantes científicamente cuando con ellas uno corre el riesgo de que pudieran ser falsas. Otra cosa ya ni
} 
Teoria dos sistemas autopoiéticos e constituição:

Luhmann e o Supremo Tribunal Federal

siquiera se admite. La ciencia se obliga a proceder de una forma arriesgada." (LUHMANN, 2006, p. 129)

${ }^{3}$ Embora sofra críticas por não ser tipicamente um Tribunal Constitucional, uma vez que o STF possui outras competências.

${ }^{4}$ FEBBRAJO; CORSI, 2015. O título do livro exalta o tema em voga: Sociology of Constitutions: A Paradoxal Perspective.

${ }^{5}$ Ao menos no que se refere à organização do Judiciário brasileiro.

6 "Para citar o celebrado paradoxo de Gunther Teubner, que 'ao que parece colocou ares de consternação - senão de apoplexia - nos rostos dos incréus', numa palestra em Florença: 'Quando digo 'aberto', quer dizer 'aberto' num sentido fechado' (!)” (KING, 2009, p. 65-66).

${ }^{7}$ Como demonstra Michael King: KING, 2009, p. 62-66.

${ }^{8}$ O sistema jurídico possui o código binário lícito/ilícito (ou Direito/Não Direito), o qual subordina todas as suas operações autopoiética, alcançando uma clausura operacional recursiva (LUHMANN, 2005, p. 100-101).

${ }^{9}$ LUHMANN, 2002, p. 94.

${ }^{10}$ Complexidade entendida como a existência sempre de mais possibilidades do que se pode realizar. Do conceito, há a noção de elemento e de relação, i.e., complexidade como aumento quantitativo dos elementos, sendo não mais possível relacionar todos elementos entre si. Assim, implica uma seleção forçada, pressão seletiva, a qual implica a contingência, ou seja, as possibilidades apontadas para as demais expectativas poderiam ser diferentes das esperadas, possuindo a possibilidade de desapontamento (LUHMANN, 1983; LUHMANN, 1991).

11 "Aumento de complejidad mediante reducción de complejidad: las adquisiciones evolutivas eligen las reducciones de forma tal que pueden ser compatibles con una complejidad más alta, y con frecuencia (y la mayoría de las veces gradualmente) es lo único que las hace posibles" (LUHMANN, 2007, p. 400-401).

12 Por contingência entendemos o fato de que as possibilidades apontadas para as demais experiências poderiam ser diferentes das esperadas (...). Em termos práticos, (...), e contingência significa perigo de desapontamento e necessidade de assumir-se riscos" (LUHMANN, 1983, p. 45-46).

${ }^{13}$ Aliás, tal menção à Luhmann foi realizada também na reclamação n. ${ }^{\circ} 6393$ pelo próprio Min. Ricardo Lewandowski, cujo objeto da reclamação constitucional consistia exatamente na afronta à decisão da ADPF 6393.

14 Assentou-se tratar de norma pré-constitucional, uma vez que a LC 64/90 antecedeu a promulgação da Emenda Constitucional n. ${ }^{\circ}$ 04/94, a qual determinou a nova redação do $\S 9^{\circ}$ do art. $14 \mathrm{da} \mathrm{CF} / 88$.

15 Portanto, a LC 64/90 não havia ainda sido alterada pela Lei Complementar n. ${ }^{\circ}$ 115/10, conhecida por lei da ficha limpa.

${ }^{16}$ Registre-se que esse entendimento vem a ser alterado no julgamento da ADI n. ${ }^{\circ} 4578$ - teve como objeto a LC 115/10 -, onde se propôs um overruling dos precedentes relativos à matéria da presunção de inocência nos casos de inelegibilidade, conforme assentado pelo Min. relator Luiz Fux. 
${ }^{17}$ Com a Lei Complementar n. ${ }^{\circ}$ 135/10 (conhecida por Lei da Ficha Limpa), o STF foi instado a mudar de posicionamento, reconhecendo a não aplicabilidade do princípio da presunção de inocência ao direito penal e processual penal, de modo a bastar a condenação por órgão judicial colegiado para o efeito de inelegibilidade (ADI n. ${ }^{\circ} 4578$, ADCs ns. ${ }^{\circ} 29$ e 30).

${ }^{18}$ A ADI foi julgada parcialmente procedente em razão da inconstitucionalidade do art. 35-A da Lei 11.300/06, tendo em vista que os princípios da razoabilidade e da proporcionalidade implicam a inconstitucionalidade da proibição de divulgar pesquisas eleitorais a partir do décimo quinto dia anterior até as dezoito horas do dia do pleito, consoante voto do Min. relator Ricardo Lewandowski.

19 “A denominhada matriz pragmático-sistêmica de Direito, cujas possibilidades e vantagens restam estabelecidas no capítulo anterior, pode ser dividida, para efeitos epistemológicos, em duas fases: 1) a primeira, na qual Luhmann aperfeiçoa, após seus estudos em Harvard, o estruturalfuncionalismo de Parsons. É nessa fase que se colocam conceitos fundamentais para o desenvolvimento da fase posterior. 2) a autopoiética (ou autopoietológica), que representa um avanço em relação à primeira, e que traz consigo as idéias biológicas de Maturana e Varela" (SCHWARTZ, 2005, p. 51).

${ }^{20}$ Então, embora, em seu livro, Luhmann conceitue o procedimento como sendo um sistema (Luhmann, 1980, p. 39), ao relê-lo sob uma perspectiva autopoiética, é possível conceituá-lo como sendo uma estrutura de um sistema: "A tese, portanto, é de que, em termos de Sistema do Direito, a Legitimação pelo Procedimento luhmanniana pode exercer este papel de estrutura estabilizante, desde que relida pela ideia de autopoiese e entendida exatamente como uma estrutura, que consiga despertar o sentido de aceitação da decisão" (WEBBER, 2013, p. 292).

${ }^{21}$ Com base na teoria dos sistemas autopoiéticos, o sistema social se diferencia internamente em sistema da sociedade, sistema de interação e sistema organizacional (RODRÍGUEZ; ARNOLD, 2007, p. 153).

22 "Daí por que, posteriormente, o próprio conceito de positividade é considerado como insuficiente, na medida em que pode ser censurado como 'decisionista' ou supor uma contraposição ao conceito de direito natural. (...) Nessa perspectiva, a noção de autopoiese (autorreferência, autonomia ou fechamento operacional, 'autodeterminidade') do direito passa a constituir o cerne do conceito de positividade” (NEVES, 2008, p. 79-80).

23 "The lawyers observe economic actions under the code legal/ilegal and misread economic processes and structures as sources of law. Vice versa, clever economic actors misread legal normas under the economic code as bargaining chips, as new opportunities for profit-making" (TEUBNER, 1997a, p. 161).

24 "Por de pronto volvemos a repetir: ni las leyes, ni los contratos se encuentran ante el imperativo de decidir. La validez del derecho se puede cambiar (o dejar cambiar) con la selección de estas formas. A este respecto, sólo los tribunales viven una situación de excepción. Puede que las leyes y los contratos por razones políticas o económicas estén obligados a tomar una decisión. Pero estas son coacciones de otro tipo, ante las cuales el sistema del derecho está en libertad de decidir si son jurídicamente relevantes." (LUHMANN, 2005a, p. 382).

25 Desenvolvimento esse aprendizado, no caso entre Tribunais, há o conceito de "transconstitucionalismo" originário de Marcelo Neves. Ver: NEVES, 2013.

26 “A função do processo da eleição política (contrariamente a outras formas de alistamento) não reside, afinal, exatamente na orientação da indicação oficial dos objetivos para selecionar os melhores representantes do povo para os cargos políticos. (...). Proporciona a este uma R. Fac. Dir. UFG, v. 41, n. 3, p.206-229, set/dez. 2017

ISSN 0101-7187 
Teoria dos sistemas autopoiéticos e constituição:

Luhmann e o Supremo Tribunal Federal

complexidade elevada e uma indeterminação estrutural, e sobretudo uma certa impossibilidade de cálculo da situação decisiva como estímulo para a construção interna do sistema e eliminação de alternativas. (...). A eleição obriga, além disso, o indivíduo a eliminar por si um grande número de motivos possíveis de decisão (ou a especificá-los em outros papéis de puro interesse) e descongestiona com isso o sistema político do compromisso direto com outros papéis sociais. Desta forma serve finalmente para absorção dos protestos. Que as suas decisões encontrem continuamente adesão, dificilmente pode ser assegurado através da organização de eleições, mas um sistema político criado por meio de eleições pode conseguir tantas alternativas que se pode autolegitimar num processo seletivo de decisão" (LUHMANN, 1980, p. 142-143).

${ }^{27}$ Predictions of future events tend to be rarity within the social sciences. It is an even more rare occurrence when predicted events come to pass. Niklas Luhmann's predictions on the future of global law is a memorable exception" (FISCHER-LESCANO; TEUBNER, 2004, p. 999-1000).

28 "The important thing here is that deliberative democratization is not seen as being confined to political institutions but is explicitly considered in its extension to social actors in the national and the internacional context" (TEUBNER, 2004, p. 11)

29 "Thus, a kind of constitucional competition is set into motion by the autonomation of global sub-constitutions" (TEUBNER, 2004, p. 15).

30 "A consequência direta [referindo-se ao fenômeno da creeping constitutionalisation] é uma ausência de constitucionalização do sistema jurídico, e, portanto, de uma creeping constitutionalisation em países periféricos" [grifou-se] (SCHWARTZ, 2007b).

31 "In the nation-state, the glare of the political constitution has been so blinding that the individual constitutions of the civil sectors have not been visible, or at best, have appeared as part of political constitutions. And, on the global scale, too, they are equally present, albeit only latently, and, remarkable as it may seem, invisible to the naked eye" (TEUBNER, 2004, p. 18).

${ }^{32}$ Assinale-se que Marcelo Neves diverge da ideia de Constituição Civil de Teubner, porquanto, ao verificar a lex mercatoria, há uma deficiente autonomia do Direito perante os processos econômicos globais, i.e., uma sobreposição do código da Economia nas operações e estruturas jurídicas (NEVES, 2013, p. 112-113). 